\title{
Sobre fundação
}

\author{
( P A R E C E R )
}

\section{S. Soares de Faria}

No testamento de D. H. ha uma disposição em que institue duas fundações, sendo uma em S. Paulo, para a qual, entre outros destinou

os remanescentes dos seus bens.

Ainda, por declaração expressa, considerou instituida a fundação, deixando a cargo dos seus testamenteiros as minucias da instalação, organização e manutenção, especificando as pessoas que deviam ser beneficiadas.

Isto posto, pergunta-se:

1. - - Essa disposição encerra um legado ou é uma verdadeira instituição de herdeiro?

2. - E válida a disposição, deve ser tida como herdeira a Fundação organizada e instalada de acôrdo com os preceitos do testamento?

\section{AO PRIMEIRO}

A questão é hoje pacífica e a solução que consagra a segunda hipótese já tem a sanção da nossa Côrte de Apelação. De feito, não se trata de legado, porque a testadora deixou à Fundação, não sómente bens certos e determina- 
dos, mas a totalidade de seus bens, com dedução dos legados. A sua fortuna foi distribuida parte em legados, mas a parte restante, o remanesconte de seus bens foi deixada à Fundação, e justamente a deixa assim formulada constitue, no dizer de Dias Ferreirat, a essência da instituição de herdieirlo.

A Fundação é, pois, por fôrça dessa disposição, herdeira e não legatária, herdeira dos remanescentes, da totalidade dos bens, da sua universalidade, após a dedução dos legadios.

E' ainda, e no conceito de notavel monografista, herdeira universal, porque

"Se poi il testatore, dopo aver scritto legati a titolo particolare o di complessi di cose, determinate in concreto, chiuda le sue disposizioni, dichiarando di lasciare il resto dei suoi beni, il $d i$ più dell'eredità o della sostanza ereditaria ad un Sempronio, si avrà ancora una disposizione a titolo universale, e questa pure dovrà dirsi di residuo, perchè compreenderà tutta la restante sostanza ereditaria, meno quelle parziali detrazioni che formeranno oggetto dei legati". (V. Vitali, Dille Successioni, II, n. ${ }^{\circ}$ 1379).

E já anteriormente, no n. ${ }^{0} 1.378$, o mesmo VitToRe VITALI assinalava ser indubitavel tratar-se de uma disposição a título universal

"dappoichè il lasciato di tutto il resto del patrimonio, cioè dell'eredità o dei beni, non comprende un'aliquota di una cosa particolare o di un complesso di singoli oggetti, come di mobili o di immobili determinati loco et natura, mas di una universalità o totalità di cose; la quale è suscettiva di aumento e di diminuizione: e, sebbene possa sotto di sè comprendere cose particolari, nondimeno di 
queste si fa astrazione, sostanziandosi in quella sola idealità giuridica patrimoniale, che investe il chiamato della qualità giuridica di erede".

Confere: Losana - Digesto Italiano vol. XXII, P. IV, Successione Testamentaria, 22-29.

'A questão é alias pacífica entre os nossos juristas e a doutrina de V. Vitali é sufragada, entre outros, e invocamos o maior deles, por Terxeira de Freitas, que, embora considerando como rústico esse modo de instituir herdeiros, reconhece que o legatário de tais remanescentes era herdeiro instituido e não simples legatário, como se póde ver em "Testamentos e Sucessões", ed. de 1881, p. 37.

Recentemente foi ainda formulada por Itabaiana

"O que carateriza a instituição de herdeiro é o fato de suceder ele em todos ou nos remanescentes dos bens". (Direito das Suciessões, 2." ed., pg. 32-33).

e por Catrlos Maximiliano, no seu recentíssimo tratado, com apoio em HerzZfelder, vol. V, pag. 411

"De igual modo se opina, e pelo mesmo fundamento, quanto ao titular dos "remanescentes". Ex.: "Deixo a $B$ a casa em que móro; a $C$, o resto dos meus bens" ( $C$ é herdeiro; $B$ legatário). Caibam 100:000\$000 a $\mathrm{B} ; 200$ rezes a $\mathrm{C}$; e os remanescentes a D" (Considera-se herdeiro só o ultimo). Vol. I, pag. 655.

\section{AO SEGUNDO}

E' indiscutivel a validade da cláusula que instituiu a fundação, pois nela se concentram as elementos essenciais à sua creação, exigidos pelo artigo 24 do Codigo Civil: 
testamento;

dotação especial de bens livres;

especificação do fim a que se destina.

Não só instituiu herdeira do remanescente, como ainda foi previdente a testadora, fazendo tambem uma dotação especial, afim de melhor garantir-lhe a existência e assegurar uma util e proveitosa atuação, no desenvolvimento dos seus objetivos.

Ao revez do que em outro testamento se verificou o do Com. A. Z. - teve a testadora o cuidado de minudentemente especificar os beneficiários, entre os quais se incluem.

os emprgeados das Cias. A. P. e C. S. P., inválidos e impossibilitados de trabalhar por moléstia e velhice.

Tambem não deixou vago e indeterminado o fim da fundação, mas precisou-o, de modo irrefragavel, quando determinou que fossem os bens, na sua metade, destinados à creação e manutenção de asilos de beneficiência, para auxílio e assistência das pessôas que mencionou. Aí se depara o fim determinado - proteger as pessôas ligadas às empresas que o marido da testadora dirigiu e impulsionou fim, em verdade, possivel e lícito. Enfeixa, pois, os extremos apontados por Ferrara, e, si precisamente no fim encontra a fundação a sua individualidade, é certo que se não póde negar esta à fundação creada no testamento.

Não lhe falta, pois, o essencial conteudo - a determinação de um fim suficientemente preciso da fundação, a que alude Von Thur, citado por Espindola, e, no dizer deste, talves o mais notavel comentador da parte geral do C. Civil Alemão.

Está aí o fim suficientemente individualizado, de Plank não determinado de um modo genérico e vago (Regelsberger), mas claro, preciso, inconfundivel. 
Nem se objete que a fundação não póde ser considerada herdeira porque não estava ainda legalmente organisada em face do disposto nos artigos 1.717 e 1.718. Mas o disposto no art. 1.718 refere-se evidentemente às pessoas naturais

a indivíduos não concebidos até a morte do testador

e não póde ser aplicado por analogia, sem maior atenção, às pessoas jurídicas, às fundações, desprezando-se os artigos do Código que a este instituto se referem. Mas, aceitando-se a interpretação analógica, esta póde deixar de ser feita ao arrepio dos direitos da fundação. Porque esta já estava creada, legalmente instituida, porque formada de acôrdo com o preceito que autoriza a sua constituição em testamento, com todos os elementos necessários e indispensaveis à sua vitalidade.

E si a lei concede a capacidade hereditária aos indivíduos concebidos até à morte do testador, a um embrião - um embrione, una speranza d'uomo - na frase de VITTORE Vrtali (vol. I, pg. 634), ainda no estado o mais rudimentar, porque a concepção póde ter-se dado nos últimos dias de vida, e a personalidade só aparecerá com o nascimento com vida, como negá-la a quem já tem uma existência certa, por ter sido creada em consonância aos preceitos legais?

Surgem para a vida as fundações quando o testador põe, em testamento ou em escritura publica, a vontade de crear tais institutos, acompanhandora do fim certo e determinado, da dotação dos bens necessários à efetiva realização do fim visado, precisando os beneficiários. $O$ instituto foi creado e, com a eficiência do testamento, tornou-se certa a sua existência.

Si a fundação existe, porque foi creada, em testamento, porque a vontade da testadora a gerou, como negar-lhe a capacidade sucessória, porque a sua personalidade jurídica só lhe advem do registo? 
Nem se diga que é indispensavel a corexistência do elemento de fato ou material e um elemento de direito ou formal. Basta que exista o primeiro, isto é, basta que a fundação tenha sido creada em testamento, com os carateristicos de validade, porque

a fundação em todo sentido se equipara ao indivíduo, e, portanto, ao nascituro.

o direito da coletividade fica suspenso, em potência, como o do nascituro, e, como o deste, retrotrái até a abertura da sucessão, desde que é fundada integralmente, ou apenas legalizada (se já existia), a destinatária da liberalidade. (MAxIMILIANo, vol. I, pg. 150).

E o eminente ministro da nossa Suprema Côrte invoca em prol da sua opinião uma fieira de pandectistas dos mais acatados, como Escher, Crome, HerzFelder, ENDEMNn e Strohal.

A Côrte de cassação de Turim resolveu, no sentido acima, uma questão idêntica, aplicando às pessoas jurídicas a teoria do conceptus pro nato habetur, com estas considerações irretorquiveis :

"Dal momento che i corpi morali legalmente riconosciuti sono equiparati alle persone fisiche, non può esservi veruna incongruenza legale a che siano ai medesimi applicate quelle stesse norme, che regolano la capacità di succedere delle persone fisiche, salve, ben inteso, le speciali eccezioni : e cosi, come i concepiti sono capace di succedere, tuttoche la personalità giuridica dipenda dai fatti posteriori, cosi pure le fondazioni di corpi morali possono essere instituite eredi, quantumque il loro riconoscimento sia ancora di là da venire" (Sentença de 31 de julho de 1879, apud Lomonaco, Diritto Civile Italiano, vol. IV, 123). 
A igual resultado chegou a jurisprudência administrativa francesa, admitindo a validade do processo consistente em considerar o reconhecimento legal operando retroativamente, até o dia do falecimento, meio a que aderiram PlANiOL, Ripert e Trasbot.

Tal jurisprudência é pacifica. O Conselho de Estado concede

"volentiers à l'établissement qu'il reconnait d'utilité publique l'autorisation de recevoir la liberalité qui a servi à le fonder, faisant ainsi rétroagir la reconnaissance au jour du déccès du fondateur et appliquant aux fondations la maxime traditionelle, infians conceptus pro nato habiotur" (JosseRutND, Droit Civil Positif, III, n. ${ }^{\circ}$ 1910).

No mesmo sentido, anos depois, decidia a Côrte de Apelação de Bologna:

"Se lo stesso diritto romano, cosi religiosamente e giustamente osservante della verità delle cose e del rispetto ai principi di diritto, pure riconosceva la capacità di succedere nell'individuo soltanto concepito, non si saprebbe perchè in un tempo in cui, in nome del pratico interesse, si è tanto proclivi a passar sopra alle forme e anche talvolta alle incomode consequenze della logica legislativa, si dovesse poi negare la capacità di succedere ad un ente morale, la cui esistenza futura non è venutale e fortuita, come quella di una persona fisica soltanto concepita, ma è preordinata e sicura per la disposizione del testatore".

$\mathrm{Na}$ verdade uma outra interpretação seria, na afïmação de RiccI, ilógica e improcedente

"In fatti si esse a creduto derogare al principio che l'erede deve essere persona capace di ricevere al tempo della aperta successione, in favo- 
re della prole nascitura di una persona vivente e, nello scopo, ben ristretto di conservare $i$ beni a vantaggio di una generazione futura, come av vrebbe potuto non derogare al rigore di questo principio in favore di ente morali, la cui esistenza e conservazione interessa altamente alla società, alla cività ed alla umanità, sicome quelli che sono intesi a difondere il benessere, $i$ soccorsi della carità e l'istruzione nelle diseradate classi sociali? (Diritto Civile, vol. IV, n. 289).

Essa a bôa doutrina que, si não fosse aplicada na espécie da consulta, deixaria ao desamparo os dignos operários das empresas, que a testadora, no imenso reconhecimento, pôs a mira em proteger, privando-os, quando necessitados, da farta messe de recursois que a fundação deverá distribuir.

E' tão procedente é que, como já salientou MaximiliaNo, o Código Civil Alemão e os seus mais reputados comentadores a abraçaram, acentuando muitos que bastaria, para resolver a questão, o dispositivo do art. 1.893, vale dizer o que, no mesmo monumento legislativo, recebia a tradicional ficção respeitante ao nascituro.

Aos autores invocados pelo douto autor do mais recente tratado, acrescentaremos LEHMitN

"Mit der Genemigung ist die Stiftung entstanden. Wird Sie erst nach dem Tode der Stifters genemigt, so gilt sie für die Zuwendungen des Stifters als Schonvor dessen Tode entstanden - 684 (Fiktion).

Não era necessária a consagração expressa no texto do. $\S 84$ : bastaria a exceção do art. 1.923 já invocado:

"Die Rückwirkung ist wichtig bei einer Stiftung, die vom Stifter zum Erben eingesetzt worden ist. Erbe kann nur werden, wer, zur Zeit der 
Erbfalls schon leht (1923). Auf grund der Fiktion wird die hinterher erst genehmigte Stiftung so behandelt, als ob sie schon vorher entstanden sei, dem Erfordernis des 1923, ist also genügt. (Algemeinen Teil des Bürgerlichen Gessetzbuches, 470).

Outra não é a lição de Rudolf Schmidt, o douto professor da Universidade de Halle, para quem

die Stiftung für die Zuwendungen des Stifters als schon vor dessen Tod entstanden zu Gelten haben (Bürgerliches Recht, 53).

O tratado de ENNEcERus, na edição revista por NiPPERDEY, professor da Universidade de Colônia, salienta que, no caso como o da consulta, em que ha no testamento a creação, com todos os elementos de vitalidade, de uma fundação, ha a presuposição de sua existencia desde a morte do testador

so liegt im Wahrheit ein Vermächtnis au die Stiftung vor, welche als schon mit dem Erbfall entstanden gilt. (Lehrbuch des B. Recht, 344).

Não menos explicito é Cosack, para quem, em casos que tais, a fundação recebe a herança pelo efeito retroativo do reconhecimento

wenn die Stiftung die zu ihrer Entstehung erforderliche staatliche Genehmigung rst nach dem Tode des Erblassers erlangt-wie in der übergrossen Mehrzahl der Fälle - erwirbt sie die Erbschaft mit rückwirkender Kraft am Tage des Erblassertodes. (Lehrbuch des Bürgerlichen Rechts, zweiter Band und Zweite Abteilung, 373, II).

Eis porque sustentamos ser indiscutivel a validade da clausula em exame. 